\title{
STABILITY IMPROVEMENT OF A FULLY SUPERCONDUCTING GENERATOR BY FUZZY LOGIC CONTROL R. A. F. Saleh
}

\author{
Electrical Engineering Department, \\ Faculty of Engineering, Menoufiya University
}

\begin{abstract}
Fully superconducting generator (FSG) is one of the promising applications of superconductors in electric power sector. Meanwhile, transient stability of FSG is an important issue in developing this new machine. An approach is suggested in this paper for the design of a fuzzy logic governor controller (FLC) as a possible mean to improve the FSG stability under transient conditions. In this approach, unsymmetrical nonlinear membership functions are used, while number of FLC parameters to be properly designed is 15 parameters, including scaling factors for input and output variables along with widths and centers of fuzzy sets of input variables. A genetic algorithm is used to optimally choose all these parameters. Simulation results show that the proposed FLC leads to a significant improvement in the transient stability and performance of a FSG connected to an infinite-bus.

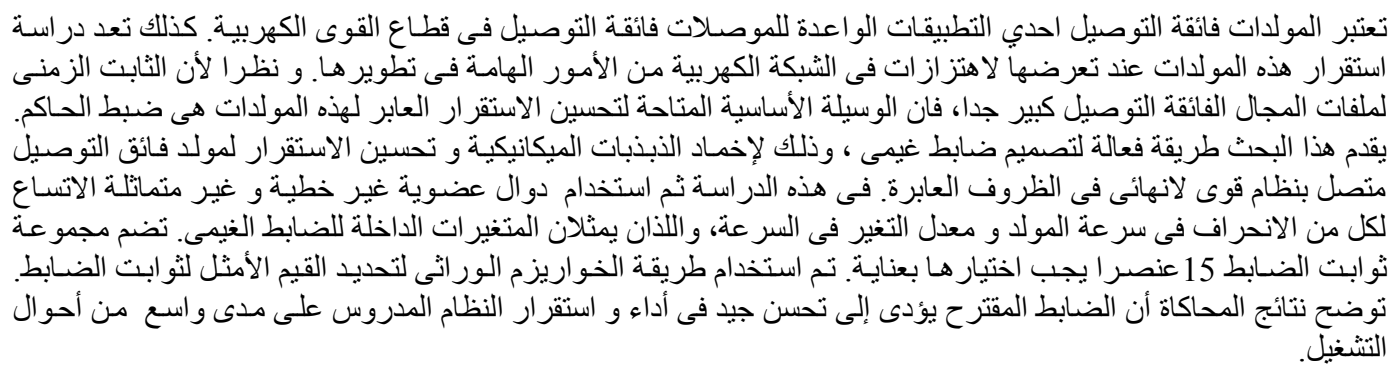

Keywords: Fully superconducting generator, Fuzzy logic control, Genetic algorithms, Transient stability.

\section{Introduction}

Although copper and aluminum have met most our needs for decades, the demand for conservation and more efficient use of electricity has brought renewed focus on superconductors. The application of superconductors in the field winding of a superconducting generator (SCG) appears to offer this machine a number of potential advantages such as higher efficiency, small size and weight, low synchronous reactance and hence improved steady state stability. On the other hand, the recent development of very low-loss, ultra-fine filament superconducting a.c. wires was the motive for developing another type of superconducting generators, called FSG in which both the field and armature windings are superconducting [1]. Compared with SCG, FSG has more potential to increase efficiency and decrease size and weight. However, FSG suffers from instability when connecting to the grid [2]. Also, this machine needs current limiting devices to prevent both of the armature and the field windings from quenching during severe fault condition [3]. The characteristics of FSG connected to a power system under many kinds of conditions must be understood exactly, since power system apparatus must be highly reliable. The main difficulty in operating the FSG with a power system is its very slow response. As the field time constant is extremely large, the excitation system is not able to change quickly the field current to restore the FSG stability. Previous studies [4-6], however, have shown that the machine stability along with its transient performance could be highly improved using governor control techniques. Recently, fuzzy logic control [7] has emerged as one of the most fruitful research areas, and many applications for enhancing power system stability have been reported in literature [8-11]. Fuzzy logic controller (FLC) is essentially a multiparameter controller, whose performance depends on the selected shape of membership functions, rule base and scaling factors. The work described in this paper is an attempt to employ the utmost power of the well-known FLC for enhancing the FSG stability. To do so, an approach is proposed and used in the design of the controller. This approach is a rather different from that used in [6], and mainly based on unsymmetrical nonlinear membership functions for input variables will be explained later on in this paper. 


\section{System Description}

A FSG-infinite bus power system, shown in Fig.1, is considered in this study [5]. Two superconducting fault current limiters (CL1, CL2) are connected in parallel and placed between the high-voltage side of the step-up transformer and the sending-end of the transmission line. In normal operation, one of the current limiters is connected to the line, and the other is stand-by and disconnected from the line. The FSG is driven by a three-stage steam turbine, which is controlled by fast acting electro-hydraulic governors fitted to the main and interceptor valves. The mathematical model of the system under study and parameter values are given in the Appendix.

\section{DESIGN PROCEDURE FOR A FUZZY LOGIC CONTROLLER}

The procedure commonly used in designing a FLC can be summarized as follows:

1- Identification of the FLC input and output variables based on understanding dynamics of the system under study,

2- Defining a universe of discourse for each variable, and a number of partitions (fuzzy subsets) within it, assigning each a linguistic label.

3- Defining a membership function for each fuzzy subset.

4- Choosing appropriate scaling factors for the input and output controller variables.

5- Deciding a defuzzification technique to convert fuzzy values into crisp values.

6- Forming the fuzzy control rules, which assign the fuzzy relationships between the input and output fuzzy subsets.

When the FLC is implemented, the following steps are performed sequentially.

1- Fuzzify the inputs to the controller.
2- Apply an inference mechanism to infer the output contributed from each rule, then aggregate all rules' outputs to form an overall fuzzy output.

3- Use the defuzzification method to obtain a crisp controller output. The basic structure of a FLC is shown in Fig. 2[5].

\section{PROPOSED FUZZY LOGIC CONTROLLER}

In this section, the determination of an efficient control signal, $U$, based on fuzzy logic is described. This signal is then introduced into the governor side as shown in Fig.3, in aim to damp the rotor oscillations after disturbances, and hence the FSG performance is improved. Speed deviation, $\omega$, and its derivative, $d \omega / d t$, are chosen as FLC input variables. Actually only " $\omega$ " signal is measured, and from it " $d \omega l d t$ " signal is computed as:

$$
d \omega(k) / d t=\left[\omega(k)-\omega(k-1) / T_{\mathrm{s}}\right]
$$

where $T_{\mathrm{S}}$ is the sampling interval. Two scaling factors, $K_{A}$ and $K_{B}$, are used to map $\omega$ and $d \omega / d t$, respectively into their predefined universes of discourse, which are divided into seven overlapping fuzzy sets; named large positive "LP", medium positive "MP", small positive "SP", zero "ZE", small negative "SN', etc. A bell-shaped membership function is assigned for each fuzzy set such that if a crisp input " $x$ " belongs to a set of range $[a-b]$ and width " $d$ ", then its degree of membership $\mu_{x}$, in this set is defined by the following function:

$$
\mu_{x}=\left\{\begin{array}{lc}
(2(x-a) / d)^{2} & \text { if } a \leq \mathrm{x} \leq c \\
(2(b-x) / d)^{2} & \text { if } c \leq \mathrm{x} \leq b \\
0 & \text { else }
\end{array}\right.
$$

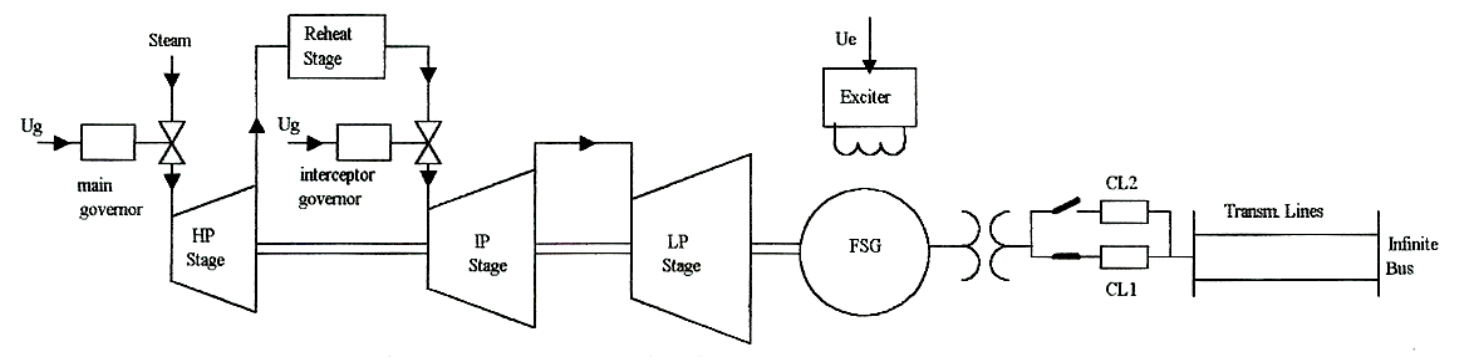

Fig.1 Fully superconducting turbo-generator[5]

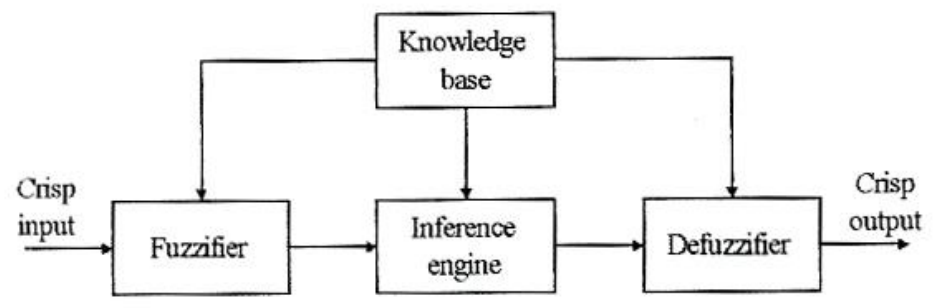

Fig.2 Basic structure of a fuzzy logic controller[5] 


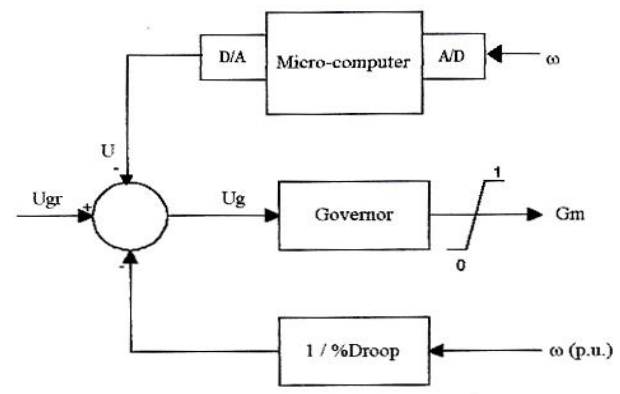

Fig.3 The governor control system

Table 1: Fuzzy logic control rules for FSG system

\begin{tabular}{|c|c|c|c|c|c|c|c|}
\hline$d \omega / d t$ & NL & NM & $\mathrm{NS}$ & $\mathrm{ZE}$ & PS & $\mathrm{PM}$ & PI \\
\hline NL & NS & PS & PM & PM & PM & PL & PL \\
\hline NM & NS & NS & PS & PS & PM & PM & PL \\
\hline NS & NM & NS & NS & PS & PS & PM & PM \\
\hline $\mathrm{ZE}$ & NM & $\mathrm{NM}$ & NS & $\mathrm{ZE}$ & PS & PM & PM \\
\hline PS & NM & $\mathrm{NM}$ & NS & NS & PS & PM & PM \\
\hline PM & $\mathrm{NL}$ & $\mathrm{NM}$ & NS & $\mathrm{NS}$ & PS & PS & PS \\
\hline PL & NL & NL & NM & NM & NS & NS & PS \\
\hline
\end{tabular}

Table 1 shows the fuzzy rules that are assigned for the FSG system [6]. Each entry in Table 1 represents a control rule, which takes the form: "IF $\omega$ is A, AND $d \omega l d t$ is B, THEN $u$ is C", where $\mathrm{A}, \mathrm{B}$, and $\mathrm{C}$ are fuzzy sets as defined by relation (2). These fuzzy rules are individually applied on the fuzzified inputs, resulting in an output fuzzy set, for each rule, clipped to a degree defined as:

$$
\mu_{c}\left(u_{i}\right)=\min \left(\mu_{A}(\omega), \mu_{B}(\dot{\omega})\right)
$$

The aggregated fuzzy outputs are converted into a single crisp value using the "weighted average" defuzzification method [12], which gives the output control signal as:

$$
U=K_{u} \frac{\sum_{i=1}^{m} \mu_{c}\left(u_{i}\right) \cdot u_{i}}{\sum_{i=1}^{m} \mu_{c}\left(u_{i}\right)}
$$

where $K_{u}$ is a scaling factor, $m$ is the number of rules giving contribution to the fuzzy output at the sampling instant considered, and $u_{i}$ is the center value of the fuzzy set in consequent $i$.

According to the structure of FLC described above, the number of fuzzy sets, to which an input value belongs at a time, depends on how much overlap between adjacent fuzzy sets. In reference [6], equally-overlapped, triangle membership functions are used for input variables. Here, the author proposes to increase effectiveness of the FLC by adopting unsymmetrical bell-shaped functions. This could be done by using fuzzy sets with different overlaps.

\section{TUNING OF FLC PARAMETERS}

So far, three adjustable parameters are aforementioned, i.e., $K_{A}, K_{B}$ and $K_{u}$. To gain more effectiveness from the proposed FLC, additional twelve adjustable parameters (six for $\omega$ fuzzy sets, and six for $d \omega / d t$ sets) are introduced into the design. Namely, $\mathrm{d}_{1}, \mathrm{~d}_{2}, \mathrm{~d}_{3}$ and $\mathrm{d}_{4}$, which stand for widths of fuzzy sets (LP, MP, SP, ZE) of $\omega$, and $\mathrm{C}_{2}$ and $\mathrm{C}_{3}$ which stand for centers of fuzzy sets (MP, SP) respectively. Similarly, $\mathrm{d}_{1}{ }_{1}, \mathrm{~d}_{2}{ }_{2}, \mathrm{~d}_{3}{ }_{3}, \mathrm{~d}_{4}{ }_{4}, \mathrm{C}_{2}^{\prime}$ and $\mathrm{C}_{3}^{\prime}$ are assigned for $d \omega / d t$ fuzzy sets. Therefore, we have now fifteen parameters $\left(K_{A}, K_{B}, K_{u}, \mathrm{~d}_{1}, \mathrm{~d}_{2}, \mathrm{~d}_{3}, \mathrm{~d}_{4}, \mathrm{C}_{2}, \mathrm{C}_{3}, \mathrm{~d}_{1}^{\prime}, \mathrm{d}_{2}^{\prime}, \mathrm{d}_{3}\right.$, $\mathrm{d}_{4}^{\prime}, \mathrm{C}_{2}^{\prime}, \mathrm{C}_{3}^{\prime}$ ) to be optimized simultaneously. This is a quite difficult problem to deal with using a trial-and-error approach. However, characteristics of genetic algorithm (GA) [13] make it able to solve such a complex problem. Therefore, GA with tournament selection and two-point crossover is utilized to optimally select these fifteen parameters. To do so, the following performance index, $J$, is used.

$J=\sum_{k=1}^{N}\left\{[k T . \omega(k)]^{2}+\left[k T . \Delta G_{M}(k)\right]^{2}\right\}$

where $\omega(k)$ and $\Delta G_{M}(k)$ are the deviations of the FSG speed and the governor valve position from their steady state values respectively. The population size in each generation of GA is chosen to be 60 strings. The crossover probability is set at 0.7 and the mutation probability is set at 0.001 .

\section{SIMULATION RESULTS}

A number of simulation studies was performed to develop and investigate the effectiveness of the proposed FLC. The performance index was evaluated, in all attempts of developing the FLC, in response to a three-phase to ground fault of 100-ms duration at the transformer high voltage terminals, with the rated output $\left(\mathrm{P}_{\mathrm{t}}=0.9\right.$ p.u, $\mathrm{Q}_{\mathrm{t}}=0.436$ p.u $)$. Variation of the performance index $J$ with the number of generations is shown in Fig.4. The optimal values selected by GA for $K_{A}, K_{B}$ and $K_{u}$ are $0.269,1.235$ and 1.984 respectively. The optimized fuzzy sets for and have taken the shapes shown in Fig. 5. 


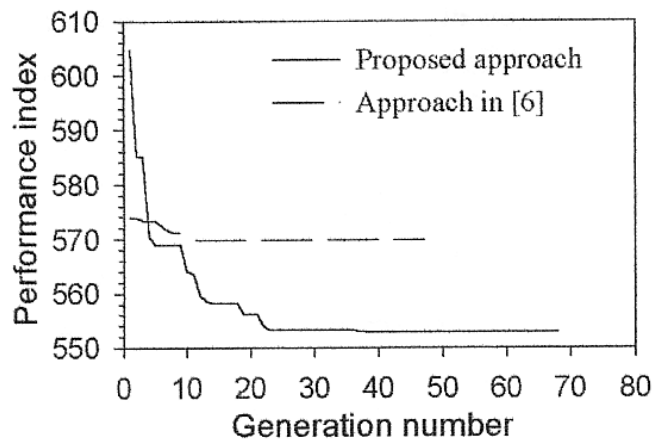

Fig.4 performance index convergence
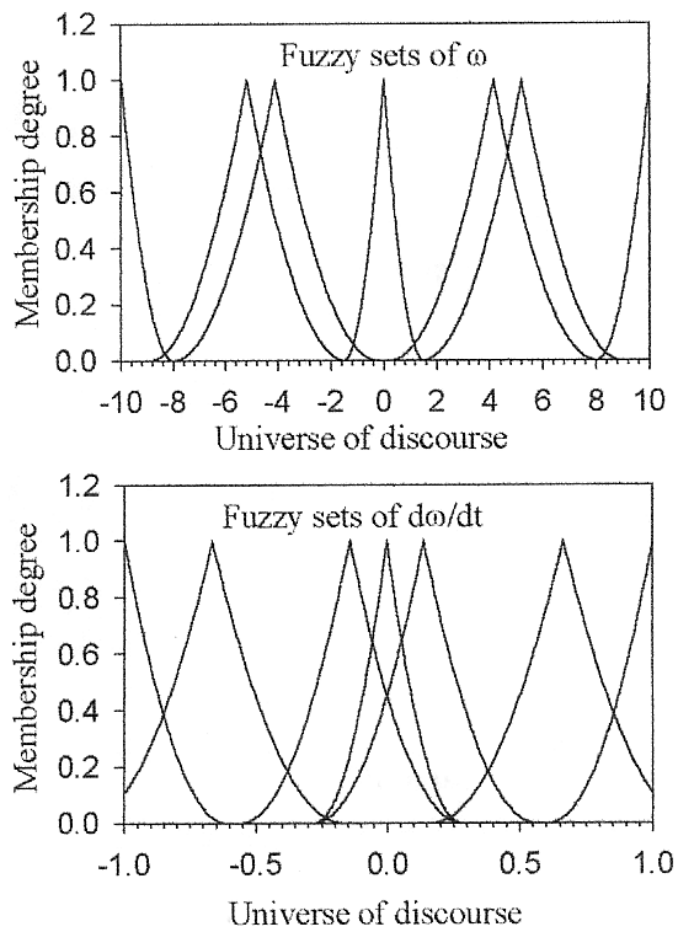

Fig.5 Optimized fuzzy sets of $\omega$ and $d \omega / d t$

In Ref. [6] the fuzzy controller was compared with a conventional controller (lead compensator) and the results have shown that the fuzzy controller outperforms the conventional one. Therefore, it was seen to compare the proposed algorithm only with that of Ref. [6], while keeping the response with speed governor (SG) in the figures to show that the machine essentially needs an additional control signal. Performance of the FSG system with the proposed fuzzy governor controller following a 3-phase short circuit fault for $100 \mathrm{~ms}$, at the operating points $\left[\left(\mathrm{P}_{\mathrm{t}}\right.\right.$, $\left.\left.\mathrm{Q}_{\mathrm{t}}\right)=(0.9,0.436),(0.8,-0.2) \mathrm{p} . \mathrm{u}\right]$, is shown in Fig. 6 and Fig. 7, Figs. 8 and 9 show the system response to a temporary (100-ms long) $5 \%$ step increase in the governor set point at the previous loading conditions. All these figures also show the system response
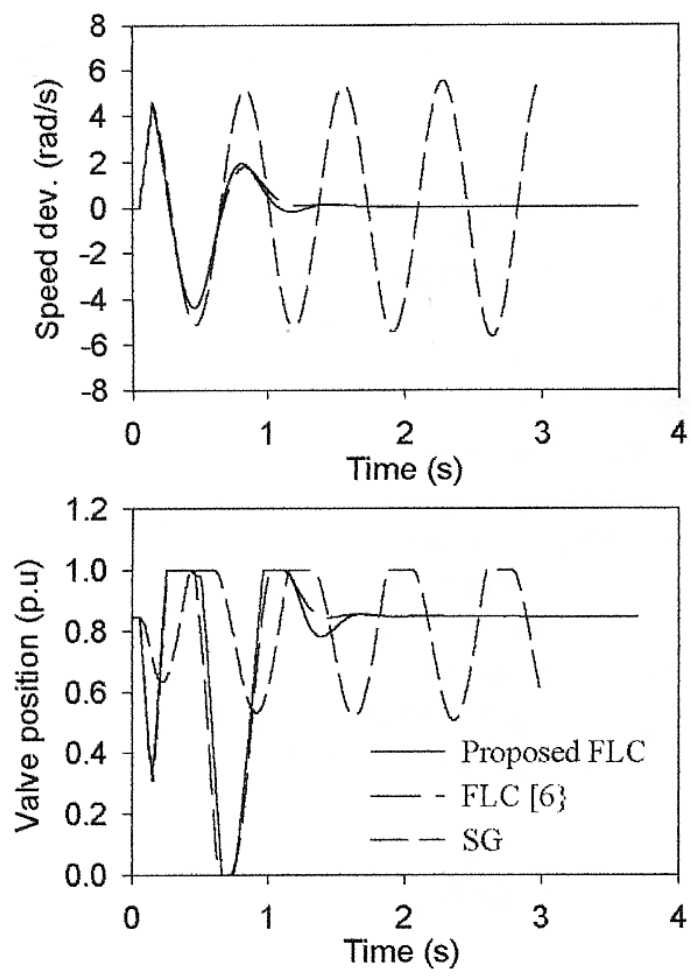

Fig.6 Response to SC; $P_{t}=0.9 \mathrm{pu}, Q_{t}=0.436 \mathrm{pu}$
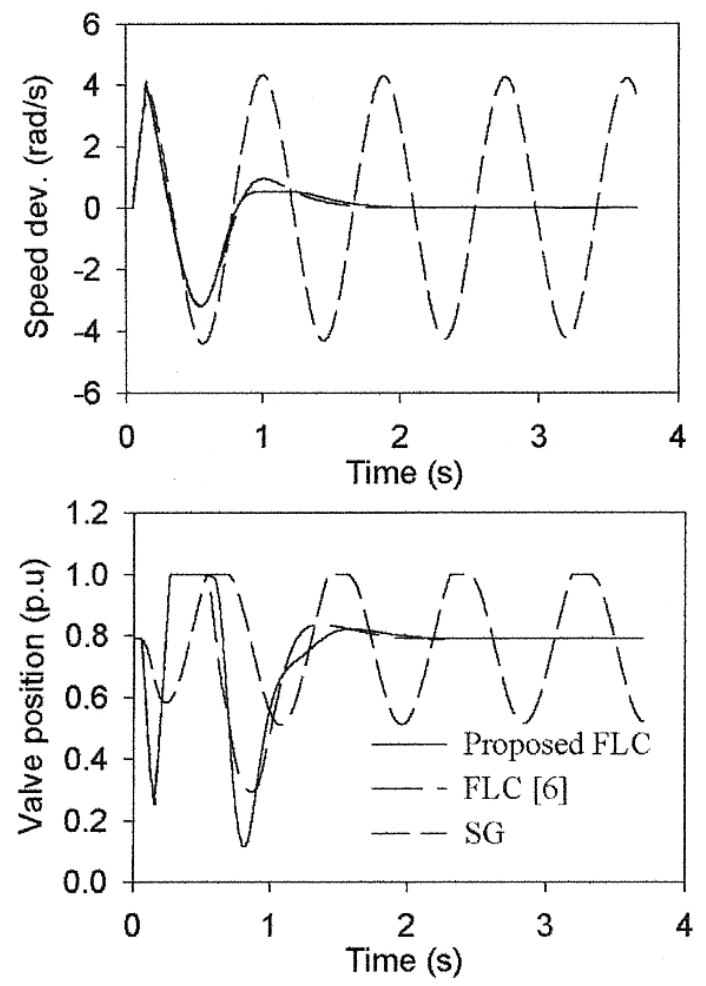

Fig.7 Response to SC; $P_{t}=0.8 \mathrm{pu}, Q_{t}=-0.2 \mathrm{pu}$

with speed governor (SG) only, i.e. without the additional control signal, $U$. The FSG dynamic performance was analyzed using the concept of damping and synchronizing torque components. The results show that the addition of the proposed FLC improves the damping coefficient $K_{d}$ by $16.5 \%$ and $150 \%$ at $\left[\left(\mathrm{P}_{\mathrm{t}}, \mathrm{Q}_{\mathrm{t}}\right)\right.$ 


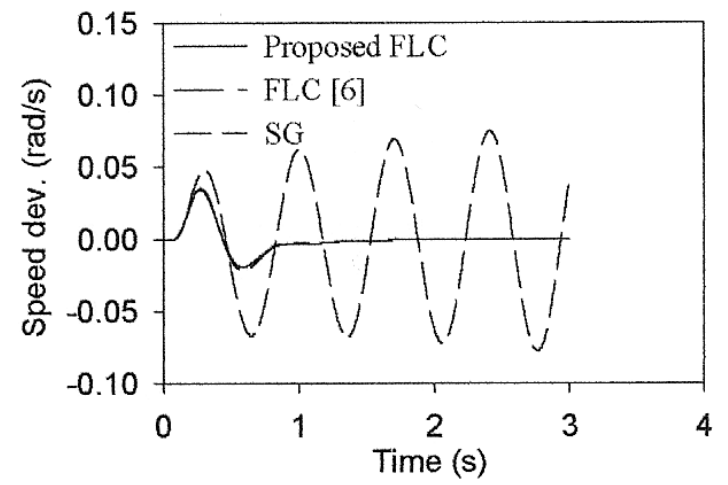

Fig.8 Response to a pulse in $\mathrm{U}_{\mathrm{gr}}$ at $P_{t}=0.9 \mathrm{pu}, Q_{t}=0.436 \mathrm{pu}$

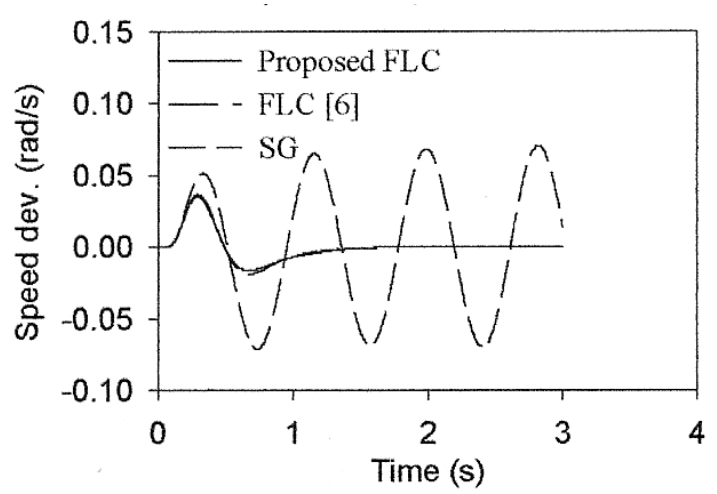

Fig.9 Response to a pulse in $\mathrm{U}_{\mathrm{gr}}$ at $P_{t}=0.8 \mathrm{pu}, Q_{t}=-0.2 \mathrm{pu}$

$=(0.9,0.436),(0.8,-0.2)$ p.u] respectively, compared with those using another fuzzy controller [6].

The simulation results show that the proposed FLC results in a significant improvement in the FSG transient behaviour and a considerable reduction in the rotor oscillations with acceptable governor valve movements. Also, although the FLC parameters are optimized for particular loading conditions and even for a particular type disturbance, they are robust and lead to more increase in the damping coefficient for other loading condition and disturbance as shown above. Meanwhile, although the time response with the proposed approach shows slight difference when compared with that of Ref. [6], quantitative measures in terms of the performance index and damping coefficient show some improvements.

\section{CONCLUSION}

This paper has presented and developed an approach for the design of a FLC for stability enhancement of a FSG. The main features of this approach are:

(1) Using nonlinear, unsymmetrical membership functions for the variables input to the controller.
(2) Optimizing the shapes of these functions by utilizing GA to optimally assign the widths and centers of input variables' fuzzy sets.

Simulation results show that the proposed controller is an efficient in enhancing FSG stability, and also provides the FSG system with more damping of the mechanical-mode oscillations than the previous FLC [6] does.

\section{REFERENCES}

[1] Tixador, P., et. al., "Electrical tests on a fully super-conducting synchronous machine", IEEE Trans. on Magnetics, Vol. 27, No. 2, (1991), pp.2256-2259.

[2] Tsukamoto, O., et. al., "Stability characteristics of fully superconducting and damperless generator connected to power grid", IEEE Trans. on Applied Superconductivity, Vol. 3, No. 1, (1993), pp.377-380.

[3] Chen, H., and Tsukamoto, O., "Stability characteristics of fully superconducting and damperless generator with excitation control in fault condition", IEEE Trans. on Applied Superconductivity, Vol. 5, No. 2, (1995), pp. 449-452.

[4] Saleh, R.A.F., "Transient stability enhancement of a fully superconducting and damperless generator using governor control", Proceeding of SICE Annual Conference, (2003), pp.176-181.

[5] Saleh, R.A.F., "Genetic algorithm-tuned fuzzy logic-based governor controller for a fully superconducting generator", Proceeding of the ninth MEPCON, Vol. 1, (2003), pp.125-130.

[6] Bishr, M.A and Saleh, R.A.F., "Design of a fuzzy logic controller for a fully superconducting generator using a genetic algorithm", Engineering Research Journal, Vol. 27, No. 2, (2004), pp.151-157.

[7] Lee, C.C., "Fuzzy logic in control systems: Fuzzy logic controller - Part I, Part II", IEEE Trans. on Systems, Man, and Cybernetics, Vol. 20, No. 2, (1990), pp. 404-435.

[8] Hassan, M.A.M., Malik, O.P. and Hope, G.S., "A fuzzy logic based stabilizer for a 
synchronous machine", IEEE Trans. on EC, Vol. 6, No. 3, (1991), pp. 407-413.

[9] Hsu, Y.Y. and Cheng, C.H., "A fuzzy controller for excitation control", IEEE Trans. on SMC, Vol. 23, No. 2, (1993), pp. 532-539.

[10] Hiyama, T., "Robustness of fuzzy logic power system stabilizers applied to multimachine power system", IEEE Trans. on EC, Vol. 9, No. 3, (1994), pp.451-459.

[11] El-Metwally, K.A. and Malik,O.P., "Fuzzy logic power system stabilizer", IEE Proc., Pt. C., Vol. 142, No. 3, (1995), pp. 277-281.

[12] Ross, T.J., "Fuzzy logic with engineering applications", New York, McGrew-Hill Inc., 1995.

[13] Goldberg, D.E., "Genetic algorithms in search, optimization, and machine learning”, USA, Addison-Wesley Publishing Co., 1989.

\section{APPENDIX}

The mathematical model of the FSG:

$$
\begin{aligned}
& p \psi_{f}=\omega_{o}\left[v_{f}-i_{f} R_{f}\right] \\
& p \psi_{d}=\omega_{o}\left[v_{d}+\psi_{q}\right]+\psi_{q} \omega \\
& p \psi_{q}=\omega_{o}\left[v_{q}-\psi_{d}\right]-\psi_{d} \omega \\
& p \delta=\omega \\
& p \omega=\frac{\omega_{o}}{2 H}\left[T_{m}-T_{e}\right] \\
& T_{e}=\psi_{d} i_{q}-\psi_{q} i_{d}
\end{aligned}
$$

The mathematical model of the turbine and governor system:

$$
\begin{aligned}
& p Y_{H P}=\left(G_{M} P_{o}-Y_{H P}\right) / \tau_{H P} \\
& p Y_{R H}=\left(Y_{H P}-Y_{R H}\right) / \tau_{R H} \\
& p Y_{I P}=\left(G_{I} Y_{R H}-Y_{I P}\right) / \tau_{I P} \\
& p Y_{L P}=\left(Y_{I P}-Y_{L P}\right) / \tau_{L P} \\
& T_{m}=F_{H P} Y_{H P}+F_{I P} Y_{I P}+F_{L P} Y_{L} \\
& p G_{M}=\left(U_{g}-G_{M}\right) / \tau_{G M} \\
& p G_{I}=\left(U_{g}-G_{I}\right) / \tau_{G I}
\end{aligned}
$$

Parameters of the system studied are:

$S=1100 \mathrm{MVA}, L_{f}=0.77, L_{d}=L_{q}=0.53, M_{f d}=0.53$, $R_{f}=0.0000029, R_{T}=0.003, X_{T}=0.15$,

$R_{L}=0.0075, X_{L}=0.195, H=3 \mathrm{~kW} . \mathrm{s} / \mathrm{kVA}$.

Turbine and governor parameters:

$\tau_{G M}=\tau_{G I}=0.1, \tau_{H P}=0.1, \tau_{R H}=10$,

$\tau_{I P}=\tau_{L P}=0.3, P_{o}=1.2$ p.u.

$F_{H P}=0.26, F_{I P}=0.42, F_{L P}=0.32$
Valve position and movement constraints are defined by:

$0 \leq\left(G_{M}, G_{I}\right) \leq 1$ and $-6.7 \leq\left(p G_{M}, p G_{I}\right) \leq 6.7$ The definitions of variables not defined in the paper are given in a "List of Symbols" below.

\section{LIST OF SYMBOLS}

$F \quad$ : fractional contribution of the turbine stage into $T_{m}$

$G_{M}, G_{I}$ : main and interceptor valve positions

$H \quad$ : inertia constant

$M_{f d}$ : mutual inductance between armature and field windings

$P_{t}, Q_{t}$ : active power and reactive power at generator terminal

$P_{o} \quad$ : boiler steam pressure

$p \quad:$ derivative operator w.r.t time

$R_{f} \quad$ : resistance of field winding

$R_{T}, L_{T}$ : resistance and self-inductance of transformer

$T_{e} \quad$ : electromagnetic torque

$T_{m} \quad$ : mechanical torque

$U_{g} \quad$ : governor actuating signal.

$V, i$ : voltage and current

$\omega_{o}:$ synchronous speed

$\omega$ : FSG speed deviation from

synchronous speed

$R_{L}, L_{L}$ : resistance and self-inductance of transmission line

$Y \quad$ : output of a turbine or reheat stage

$\psi \quad:$ flux linkage

$\delta \quad$ : rotor angle with respect to infinite bus

$\tau \quad:$ time constant of stage

MP : medium positive

SP : small positive

$\mathrm{SN}$ : small negative 